\title{
Changes in motor preparation affect the sensory consequences of voice production in voice hearers
}

Citation for published version (APA):

Pinheiro, A. P., Schwartze, M., Amorim, M., Coentre, R., Levy, P., \& Kotz, S. A. (2020). Changes in motor preparation affect the sensory consequences of voice production in voice hearers. Neuropsychologia, 146, [107531]. https://doi.org/10.1016/j.neuropsychologia.2020.107531

Document status and date:

Published: 01/09/2020

DOI:

10.1016/j.neuropsychologia.2020.107531

Document Version:

Publisher's PDF, also known as Version of record

Document license:

Taverne

Please check the document version of this publication:

- A submitted manuscript is the version of the article upon submission and before peer-review. There can be important differences between the submitted version and the official published version of record.

People interested in the research are advised to contact the author for the final version of the publication, or visit the DOI to the publisher's website.

- The final author version and the galley proof are versions of the publication after peer review.

- The final published version features the final layout of the paper including the volume, issue and page numbers.

Link to publication

\footnotetext{
General rights rights.

- You may freely distribute the URL identifying the publication in the public portal. please follow below link for the End User Agreement:

www.umlib.nl/taverne-license

Take down policy

If you believe that this document breaches copyright please contact us at:

repository@maastrichtuniversity.nl

providing details and we will investigate your claim.
}

Copyright and moral rights for the publications made accessible in the public portal are retained by the authors and/or other copyright owners and it is a condition of accessing publications that users recognise and abide by the legal requirements associated with these

- Users may download and print one copy of any publication from the public portal for the purpose of private study or research.

- You may not further distribute the material or use it for any profit-making activity or commercial gain

If the publication is distributed under the terms of Article $25 \mathrm{fa}$ of the Dutch Copyright Act, indicated by the "Taverne" license above, 


\title{
Changes in motor preparation affect the sensory consequences of voice production in voice hearers
}

\author{
Ana P. Pinheiro ${ }^{a, *}$, Michael Schwartze ${ }^{b}$, Maria Amorim ${ }^{a}$, Ricardo Coentre ${ }^{c, d}$, Pedro Levy ${ }^{c}$, \\ Sonja A. Kotz ${ }^{\text {b }}$ \\ ${ }^{\text {a }}$ Faculdade de Psicologia, Universidade de Lisboa, Lisboa, Portugal \\ ${ }^{\mathrm{b}}$ Faculty of Psychology and Neuroscience, Maastricht University, Maastricht, The Netherlands

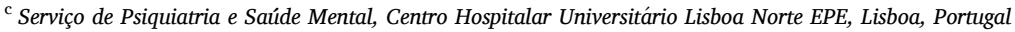 \\ ${ }^{\mathrm{d}}$ Faculdade de Medicina, Universidade de Lisboa, Lisboa, Portugal
}

\section{A R T I C L E I N F O}

\section{Keywords:}

Voice

Action

Feedback

Auditory verbal hallucinations

Psychosis

Continuum.

\begin{abstract}
A B S T R A C T
Background: Auditory verbal hallucinations (AVH) are a cardinal symptom of psychosis but are also present in $6-13 \%$ of the general population. Alterations in sensory feedback processing are a likely cause of AVH, indicative of changes in the forward model. However, it is unknown whether such alterations are related to anomalies in forming an efference copy during action preparation, selective for voices, and similar along the psychosis continuum. By directly comparing psychotic and nonclinical voice hearers (NCVH), the current study specifies whether and how AVH proneness modulates both the efference copy (Readiness Potential) and sensory feedback processing for voices and tones (N1, P2) with event-related brain potentials (ERPs).

Methods: Controls with low AVH proneness $(\mathrm{n}=15)$, NCVH $(\mathrm{n}=16)$ and first-episode psychotic patients with AVH $(n=16)$ engaged in a button-press task with two types of stimuli: self-initiated and externally generated self-voices or tones during EEG recordings.

Results: Groups differed in sensory feedback processing of expected and actual feedback: NCVH displayed an atypically enhanced N1 to self-initiated voices, while N1 suppression was reduced in psychotic patients. P2 suppression for voices and tones was strongest in $\mathrm{NCVH}$, but absent for voices in patients. Motor activity preceding the button press was reduced in NCVH and patients, specifically for sensory feedback to self-voice in NCVH.

Conclusions: These findings suggest that selective changes in sensory feedback to voice are core to AVH. These changes already show in preparatory motor activity, potentially reflecting changes in forming an efference copy. The results provide partial support for continuum models of psychosis.
\end{abstract}

\section{Introduction}

Self-initiated actions lead to sensory attenuation: sounds elicited by one's own actions are processed differently from externally generated sounds (Blakemore et al., 1998; Chen et al., 2011; Knolle et al., 2012; Wang et al., 2014). Sensory attenuation can be explained by the forward model framework (Friston, 2005; Schröger et al., 2015), which operates on the basis of an efference copy of the motor command (von Holst, 1954). For example, when speaking an efference copy of the voice is sent from sensorimotor brain regions to the auditory system via the cerebellum (Ito, 2008; Wolpert et al., 1998). Preparatory motor activity predicts sensory attenuation of action outcome (Ford et al., 2014a, 2014b; Reznik et al., 2018; Vercillo et al., 2018). Consequently, successful prediction of sensory feedback to self-initiated action allows distinguishing self from other actions (Friston, 2012; Heinks-Maldonado et al., 2007; Synofzik et al., 2010) (Supplementary Figure 1).

Changes of mechanisms related to the forward model have been linked to unusual perceptual experiences such as auditory verbal hallucinations (AVH) (Feinberg, 1978; Feinberg and Guazzelli, 1999; Heinks-Maldonado et al., 2007; Horga et al., 2014; Pinheiro et al., 2018). AVH are a cardinal symptom of schizophrenia and experienced by up to $70 \%$ of persons with this diagnosis (Waters and Fernyhough, 2017). However, they are also present in other psychiatric (e.g., bipolar disorder) and neurological conditions (e.g., temporal lobe epilepsy)

\footnotetext{
* Corresponding author. Faculdade de Psicologia, Universidade de Lisboa, Alameda da Universidade, Lisboa, Portugal.

E-mail address: appinheiro@psicologia.ulisboa (A.P. Pinheiro).
} 
(Waters and Fernyhough, 2017), as well as in $6-13 \%$ of the general population (Beavan et al., 2011) without a psychiatric or neurological diagnosis (hereafter referred to as 'voice hearers'). Phenomenological (Moritz and Larøi, 2008; Waters and Fernyhough, 2017), mechanistic and structural changes (Baumeister et al., 2017; Brunelin et al., 2006) in psychotic and nonclinical AVH have been discussed. Such observations support the psychosis continuum hypothesis, i.e., features of psychosis occur on a continuum in the general population (Johns and Van Os, 2001; Van Os et al., 2009; Verdoux and Van Os, 2002).

Psychotic patients perceive a significant change in sensory feedback to their own voice (Heinks-Maldonado et al., 2007). In sound, voice, and speech production this is reflected in an attenuated N1 suppression of the event-related potential (ERP) for self-initiated tones and voices (Ford et al., 2001b; Ford and Mathalon, 2005) that is related to AVH severity (Ford et al., 2008; Heinks-Maldonado et al., 2007) and dependent on stimulus type (Pinheiro et al., 2018). Nonclinical voice hearers (NCVH) tend to show enhanced rather than suppressed sensory feedback to the self-generated voice but not to simple tones (Pinheiro et al., 2018). These changes in sensory feedback to self-generated vocalizations likely reflect a core feature of the psychosis continuum (Pinheiro et al., 2018) or at least a risk marker for psychosis (Linscott and van Os, 2013; Perez et al., 2012). Altered N1 suppression possibly reflects neurofunctional changes in the auditory cortex, the main neural generator of the N1 (Godey et al., 2001; Näätänen and Michie, 1979; Zouridakis et al., 1998), but also in frontal (Boutros et al., 2011; Näätänen and Picton, 1987) and cerebellar regions (Knolle et al., 2013a, 2012). P2 suppression in response to self-generated tones was observed in button-press tasks in healthy participants and suggested to reflect the conscious detection of a self-initiated sound (Knolle et al., 2013a, 2012). However, P2 suppression effects have not been systematically examined in psychotic patients and NCVH.

Next to changes in sensory feedback, alterations of preparatory motor activity associated with an upcoming action may reflect a change in the formation of an efference copy (Ford et al., 2014a, 2014b). The Readiness Potential (RP) is a slow-building negative ERP deflection, starting around 1-2 s prior to a voluntary action (Deecke et al., 1984; Di Russo et al., 2017; Shibasaki and Hallett, 2006). It comprises an early phase, starting roughly $1-2 \mathrm{~s}$ before movement onset and associated with the preparation and initiation of the forthcoming action, and a late phase beginning around $500 \mathrm{~ms}$ before an action (Deecke et al., 1984; Di Russo et al., 2017; Reznik et al., 2018; Shibasaki and Hallett, 2006; Vercillo et al., 2018). The RP has been associated with increased neural activity spreading from pre-motor regions such as the Supplementary Motor Area [SMA] (early phase) to the primary motor cortex [M1] (late phase) (Ball et al., 1999; Erdler et al., 2000; Praamstra et al., 1996; Weilke et al., 2001; Wildgruber et al., 1997). These brain regions are structurally connected to the cerebellum (Haggard et al., 1995), which, in turn, plays a key role in the forward model (Doya, 1999; Ito, 2006; Kawato and Gomi, 1992). Brain activity preceding an action is particularly relevant for investigating the forward model as it was found to contribute to sensory suppression resulting from voluntary actions (Ford et al., 2014a, 2014b; Haggard and Whitford, 2004; Reznik et al., 2018; Vercillo et al., 2018). Consistent with the notion of an altered formation of the efference copy, the RP is reduced in schizophrenia patients (Ford et al., 2014a, 2014b; Luck et al., 2009; Mathalon et al., 2002; Singh et al., 1992). This alteration is related to impaired response selection and preparation but not response execution (Kappenman et al., 2016).

Persons with high AVH proneness offer a unique perspective for investigating the role of altered sensory voice feedback in AVH, avoiding typical confounds associated with medication and hospitalization in psychotic patients (Kelleher and Cannon, 2011). Direct comparisons of psychotic and nonclinical persons with high AVH proneness are lacking, although such comparisons could help specifying to which extent mechanisms underlying AVH in clinical and nonclinical voice hearers overlap (Knolle et al., 2013a, 2012). To this end, we probed sensory feedback processing in $\mathrm{AVH}$, directly comparing psychotic and nonclinical individuals varying in AVH proneness. A carefully controlled and previously validated button-press task (Knolle et al., 2013a, 2013b; 2012; Pinheiro et al., 2018) was used. Auditory potentials served as indices for functionally distinct processes of the forward model: the comparison between expected and actual sensory feedback (N1) and the conscious detection of a self-initiated sound (P2). Brain activity preceding the action (RP) was analyzed to specify the link between motor preparation and sensory feedback as formulated in the forward model framework.

We hypothesized that similar neural mechanisms are responsible for altered sensory feedback in psychotic patients and NCVH (Pinheiro et al., 2018) (see Supplementary Figure 1 and Supplementary Table 1). We also hypothesized that changes affecting the comparison of expected and actual sensory feedback (N1) in both psychotic and NCVH would be pronounced for voice compared to tone stimuli (Pinheiro et al., 2018), consistent with the phenomenology of altered perception in these participants (Waters and Fernyhough, 2017). Group differences were also expected for the P2, specifically reduced P2 suppression indicating altered conscious detection of self-initiated sounds (Knolle et al., 2013a, 2012).

We further expected groups to differ in motor preparation (RP) (Kornhuber and Deecke, 1965), associated with the formation of an efference copy (Ford et al., 2014a, 2014b), i.e., with sensory prediction per se (Pinheiro et al., 2018). Alongside with alterations of stimulus-evoked activity in voice hearers, we expected to observe a less negative RP preceding sound onset, interpretable as an altered efference copy. Finally, we reasoned that reduced coupling strength between premotor brain activity and sensory suppression in response to self-generated voices would be characteristic for voice hearers (Ford et al., 2014a, 2014b).

\section{Methods}

\subsection{Participants}

Forty-seven right-handed (Oldfield, 1971) volunteers participated in the study (Table 1): 15 participants with low AVH proneness; 16 NCVH; 16 first-episode psychotic patients with AVH. Exclusion criteria included sensory-motor handicaps; neurological illnesses that may significantly impair neurocognitive function; DSM-IV diagnosis of alcohol or drug abuse/dependency in the year preceding the study.

Nonclinical participants were recruited in a university setting by email/internet advertisements and word-of-mouth (Pinheiro et al., 2018). They were selected on the basis of their responses to the Launay

Table 1

Demographics and clinical scores.

\begin{tabular}{lllll}
\hline & CTR & NCVH & PAT & $\begin{array}{l}\text { Group comparisons } \\
(F, p)\end{array}$ \\
\hline $\mathrm{N}$ & 15 & 16 & 16 & - \\
Gender (M/F) & $5 / 10$ & $6 / 10$ & $9 / 7$ & - \\
Age (years) & 24.45 & 21.67 & 24.40 & $1.22(.307)$ \\
& $(6.07)$ & $(3.87)$ & $(5.07)$ & \\
LSHS-Total & 9.64 & 35.81 & - & $40.40(<.001)$ \\
& $(7.39)$ & $(13.75)$ & & $109.55(<.001)$ \\
LSHS-Auditory & 0.43 & $7.50(2.37)$ & 9.75 & \\
& $(0.94)$ & & $(4.84)$ & - \\
PANSS-Positive & - & - & 23.46 & - \\
& & & $(5.52)$ & \\
PANSS-Negative & - & - & 16.92 & - \\
& & & $(6.71)$ & \\
CPZ equivalent & - & - & 24.40 & - \\
(mg) & & & $(5.07)$ & \\
\hline
\end{tabular}

Note. CTR = Control Participants with Low AVH Proneness; $\mathrm{NCVH}=$ Nonclinical Voice Hearers; PAT = Psychotic Patients with AVH; LSHS = Launay-Slade Hallucination Scale; PANSS $=$ Positive and Negative Syndrome Scale; CPZ = Chlorpromazine. Standard deviation is shown in parentheses. 
Slade Hallucination Scale (LSHS) that assesses predisposition towards experiencing hallucinations in healthy participants (Castiajo and Pinheiro, 2017; Larøi and Van Der Linden, 2005; Levitan et al., 1996). Participants were assigned to the groups of low $(<2)$ or high $(\geq 5)$ AVH proneness considering their scores on the LSHS items tapping into AVH (sum of items 4, 8, and 9). Nonclinical participants completed a thorough clinical assessment that established that for those who reported AVH (NCVH), voices were distinct from thoughts, were unrelated to drug or alcohol abuse, and that participants did not have a psychiatric diagnosis in relation to voice-hearing.

Patients within 2 years of illness onset and with current AVH were recruited at the Hospital Center of Lisbon North (Lisbon). Diagnosis was established by experienced psychiatrists and confirmed by the Structured Clinical Interview for DSM-IV (SCID) (First et al., 2002). Symptom severity in psychotic patients was assessed with the Positive and Negative Syndrome Scale (PANSS) (Kay et al., 1987).

The study was approved by the institutional review board of the University of Minho, Faculty of Psychology - University of Lisbon, and University Hospital of Lisbon North. Before taking part in the study, all participants were informed about the procedures and provided written informed consent. They received a $20 €$ voucher for their participation in the study or course credit (students).

\subsection{Stimuli}

A $680 \mathrm{~Hz}$ tone (50 ms duration; $70 \mathrm{~dB}$ sound pressure level [SPL]) and a pre-recorded self-voice speech sound (vowel/a/) were presented in Experiments 1 and 2, respectively.

\subsection{Procedure}

\subsubsection{Voice recording}

Before the EEG experiments, a voice recording session took place: participants were instructed to repeatedly vocalize the syllable "ah". Recordings were made with an Edirol R-09 recorder and CS-15 cardioidtype stereo microphone. After the recording, the best voice sample of the vowel /a/ from each participant (i.e., constant prosody; maximum duration of $300 \mathrm{~ms}$ ) was selected. The voice sample was edited to eliminate background noise (using Audacity software), and a Praat script was applied to normalize intensity at $70 \mathrm{~dB}$. The stimulus for each participant was saved as .WAV file.

\subsubsection{EEG task}

In the EEG experiments, participants sat comfortably at a distance of $100 \mathrm{~cm}$ from a desktop computer monitor in a sound-attenuated and electrically shielded room.

A button-press paradigm was chosen over a speaking/listening paradigm as a more controlled way to study sensory feedback (Knolle et al., 2013b, 2013a, 2012). The paradigm comprised three conditions: auditory-motor (AMC), auditory-only (AOC), and motor-only (MOC), consisting of 100 trials each. A trial structure is presented in Fig. 1. In the AMC, a button-press instantaneously elicited a tone (Experiment 1 ) or the prerecorded voice of the participant (Experiment 2). Participants pressed a button approximately every $2.4 \mathrm{~s}$. In the AOC, participants were instructed to passively listen and attend to the tones (Experiment 1) or to their pre-recorded self-voice (Experiment 2). The acoustic stimulation from the AMC was recorded on-line and used as the auditory sequence that was passively presented to participants in the AOC. This ensured participants received the same set of stimuli in both conditions. The experimental blocks were preceded by two training blocks, with 200 trials. In the training blocks, participants were trained to tap every $2.4 \mathrm{~s}$. The second training block included visual feedback to indicate whether a trial was too slow (tapping interval $>3 \mathrm{~s}$ ) or too fast (tapping interval $<1.8 \mathrm{~s}$ ). No feedback was provided during the experimental blocks.

Data from two experiments (Experiment 1: tones; Experiment 2: selfvoice) were recorded during a single EEG session, with the presentation
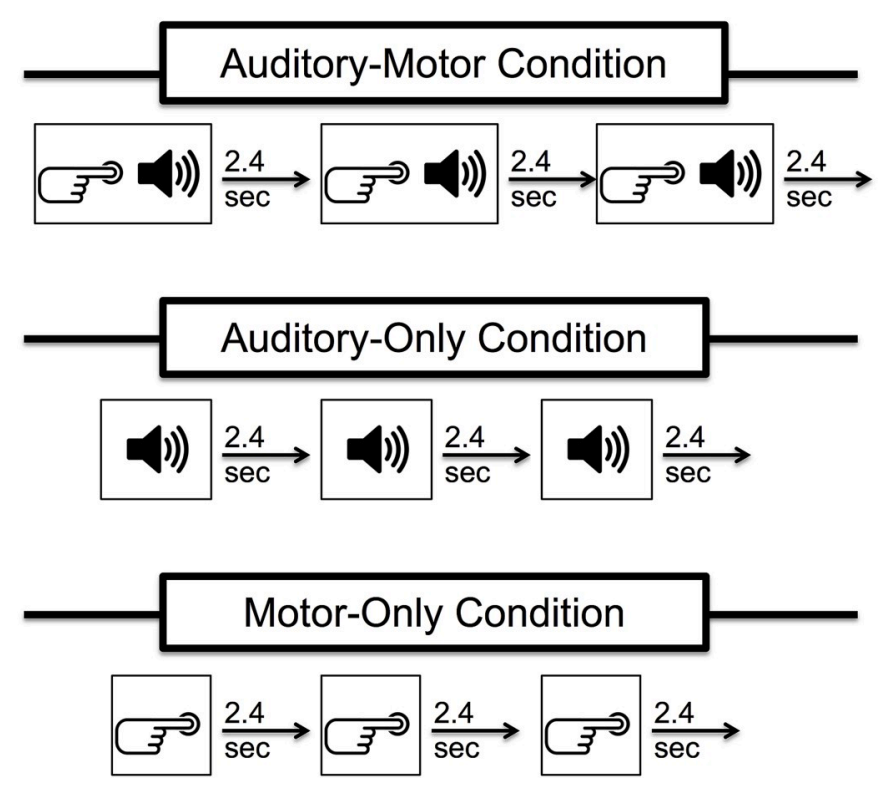

Fig. 1. Schematic illustration of the experimental conditions. Note. The MOC is a control condition for motor activity: a difference waveform was computed by subtracting the MOC from the AMC (corrected AMC [cAMC]). The critical comparison conditions are the cAMC and AOC.

order counterbalanced across participants. Stimulus presentation was controlled by Presentation 16.3 (Neurobehavioral Systems, Inc.). Stimuli were delivered via Sennheiser CX 300-II headphones.

\subsubsection{EEG data acquisition and analysis}

EEG data were recorded continuously at a digitization rate of $512 \mathrm{~Hz}$ using a 64-channel BioSemi Active Two system and stored on hard disk for later analysis.

Using Brain Vision Analyzer 2 (version 2.1.1.327), EEG data were filtered with a $0.1-30 \mathrm{~Hz}$ bandpass filter (1601 Hamming windowed filter) and referenced offline to the average of the left and right mastoids. EEG was baseline corrected using a -100 to $0 \mathrm{~ms}$ pre-stimulus interval. Tapping intervals shorter than $1.8 \mathrm{~s}$ or longer than $3.0 \mathrm{~s}$ were treated as errors and excluded from further EEG analyses. Segments were screened for eye movements, muscle artifacts, electrode drifting, and amplifier blocking. The vertical electrooculogram (EOG) was derived by subtracting the activity measured at an electrode positioned below the left eye from an electrode positioned above it. The horizontal EOG was derived by subtracting the activity measured in electrodes placed at the outer canthi of the eyes. EEG epochs with amplitudes exceeding \pm 100 $\mu \mathrm{V}$ were rejected. After artifact rejection, at least $75 \%$ of the segments per condition per participant entered the analyses. Conditions did not differ in the number of non-rejected epochs $(p>.05)$. Motor activity was subtracted from the AMC (AMC - MOC = corrected AMC [CAMC]) to allow the comparison of sensory activity elicited in the two critical conditions: AMC and AOC. This subtraction approach followed previous studies (Baess et al., 2011; Elijah et al., 2016; Ford et al., 2014a, 2014b; Oestreich et al., 2016; SanMiguel et al., 2013).

The waveforms revealed two distinct ERP peaks (see Fig. 2): a negative peak at approximately $100 \mathrm{~ms}(\mathrm{~N} 1)$ and a positive peak at approximately $200 \mathrm{~ms}$ (P2). Mean amplitudes were computed in timewindows of 80-120 ms (N1) and 160-200 ms (P2). Following our own (Pinheiro et al., 2018) and other prior studies (Knolle et al., 2013b, 2013a, 2012) to ensure comparability of findings, ERP data were extracted from four regions of interest (ROI) comprising: left anterior (F7, F3, FT7, FC3, T7, C3), right anterior (F8, F4, FT8, FC4, T8, C4), left posterior (TP7, CP3, P7, P3, PO7, PO3), and right posterior (TP8, CP4, $\mathrm{P} 8, \mathrm{P} 4, \mathrm{PO} 8, \mathrm{PO} 4)$ electrode positions.

Voltage of the RP was measured at $\mathrm{Cz}$ (see Fig. 3) and locked to the 


\section{A. Tones}

A1. CTR

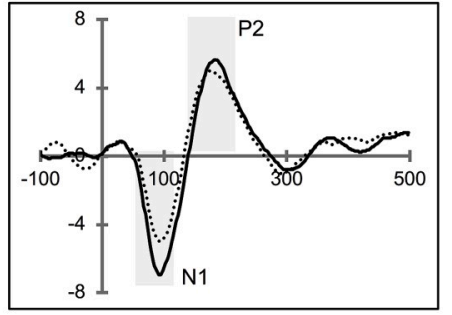

A2. NCVH

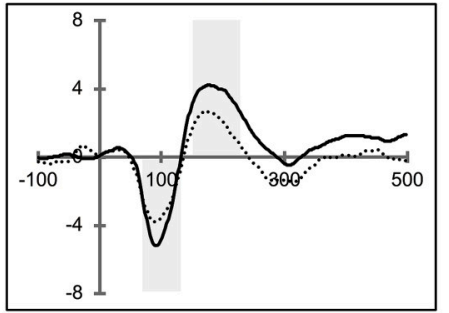

A3. PAT

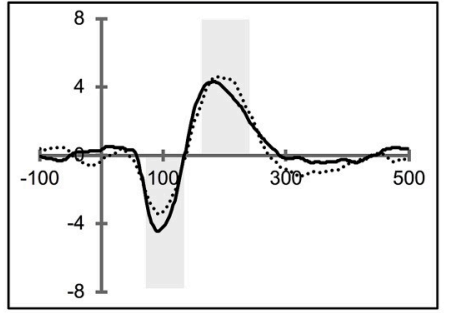

P2

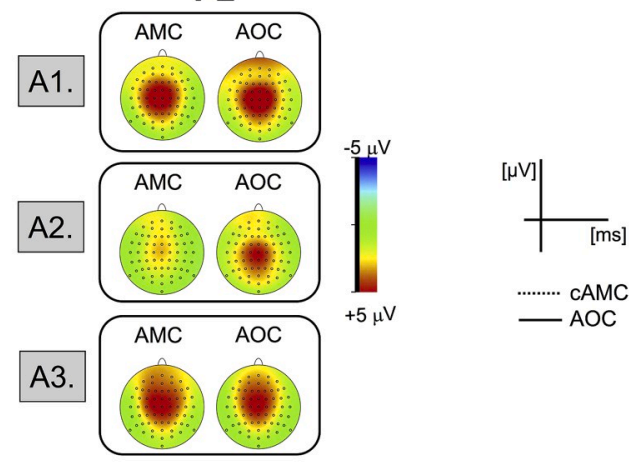

B. Self-Voice

B1. CTR

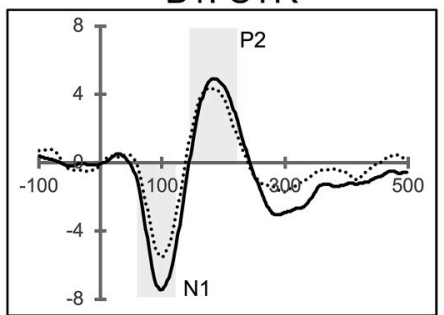

B2. NCVH

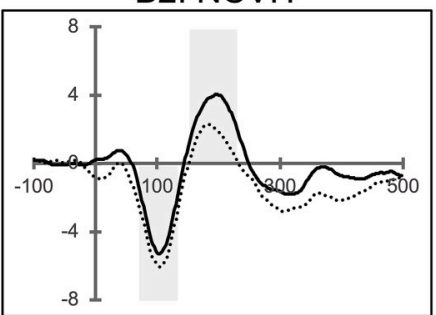

B3. PAT

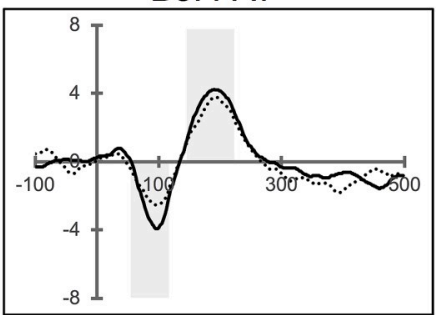

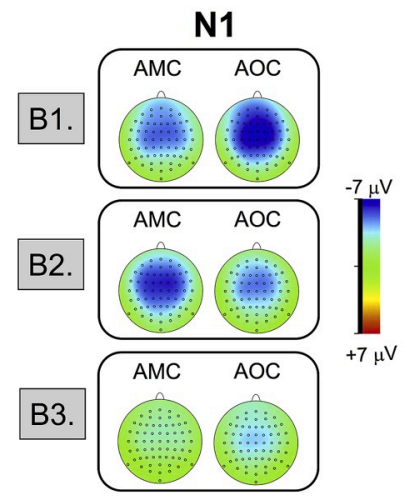
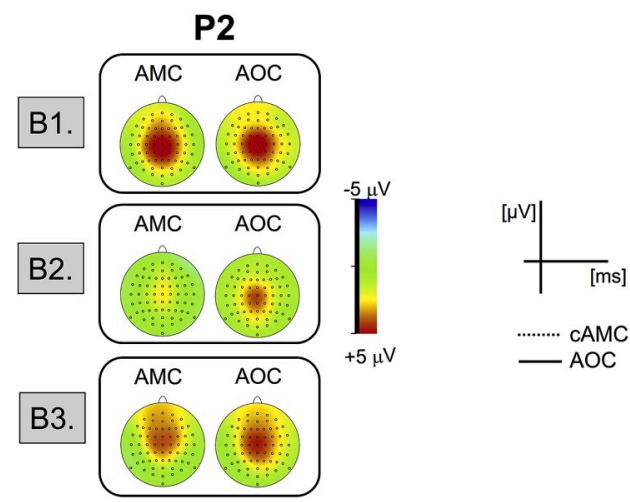

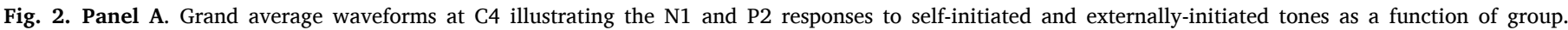

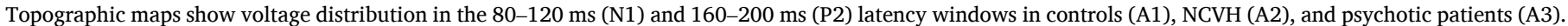

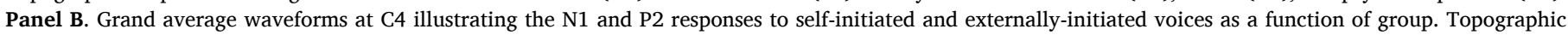

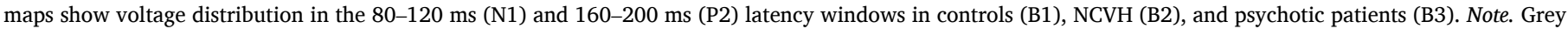

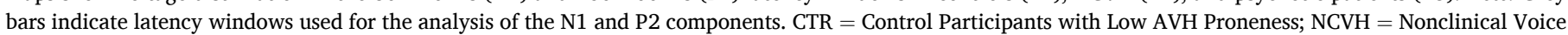
Hearers; PAT = Psychotic Patients with AVH; cAMC = motor-corrected AMC condition; AOC = auditory-only condition. 
time of the button-press as the RP's maximal amplitude is recorded over the midline vertex electrode (Deecke and Kornhuber, 1978; Vercillo et al., 2018). The early RP phase was extracted from -1000 to $-500 \mathrm{~ms}$ before action onset, whereas the late RP phase was extracted from -500 $\mathrm{ms}$ until action onset, following prior studies using similar tasks (Vercillo et al., 2018).

\subsubsection{Statistical data analyses}

Linear mixed effects models were built to fit the ERP amplitudes per participant and condition in each time-window of interest, using the lmer4 (Bates et al., 2015) and lmerTest (Kuznetsova et al., 2017) packages in the R environment (R3.4.3. GUI 1.70). ${ }^{1}$ In contrast to the more traditional repeated-measures ANOVA analysis, mixed-effects modeling allows controlling for the variance associated with random factors such as random effects for participants in ERP amplitude (Baayen et al., 2008). Considering that mixed-effects modeling can lead to more efficient estimates and more powerful tests compared to the traditional ANOVA (Bagiella et al., 2000; Boisgontier and Cheval, 2016; Jaeger, 2008), its use has been increasingly recommended in psychophysiology for the analysis of repeated-measures experiments (e.g., Bagiella et al., 2000).

The models tested the fixed effects of group (controls, NCVH, patients), stimulus type (tone, self-voice), condition (cAMC vs. AOC), and ROI (in the case of auditory potentials). Random effects terms included the subject-specific random intercepts and random slopes. The Satterthwaite approximation was applied to the REML-fitted models (Luke, 2017). The anova function from lmerTest was used to provide $p$-values for each factor, calculated from the $F$ statistic.

\section{Results}

\subsection{Behavioral results}

Participants performed correct taps (i.e., tapping interval no longer than $3 \mathrm{~s}$ and no shorter than $1.8 \mathrm{~s}$ - Knolle et al., 2012) in at least $68 \%$ of trials. Means and standard deviations of tapping intervals are presented in Table 2. No significant group differences were observed in the response patterns for the AMC and MOC conditions, both in terms of correctness or duration of tapping intervals $(p>.05)$.

\subsection{Auditory potentials}

N1: The N1 was significantly modulated by condition $(F(1,693)=$ $14.744, p<.001)$, stimulus type $(F(1,693)=8.806, p=.003)$, and group $(F(2,44)=6.030, p=.005$; see Fig. 2). Furthermore, group interacted with stimulus type and condition $(F(2,693)=4.716, p=$ .009).

We confirmed that the $\mathrm{N} 1$ was suppressed (i.e., less negative) in response to self-initiated compared to externally generated sounds ( $\beta=$ $-0.660, \mathrm{SE}=0.248, t(693)=-2.665, p=.008 ; 95 \%$ CI: $[-1.146$, $-0.175])$. Further, N1 amplitude was more negative for the self-voice than for self-initiated tones $(\beta=-1.182, \mathrm{SE}=0.240, t(693)=$ $-4.927, p<.001$; 95\% CI: [-1.653, -0.712$])$. The N1 was generally less negative in patients compared to controls $(\beta=-1.489, \mathrm{SE}=0.552, t$ $(60)=-2.697, p=.009 ; 95 \%$ CI: $[-2.571,-0.407])$, and tended to be less negative in patients compared to NCVH $(\beta=-1.001, \mathrm{SE}=0.543, t$ $(60)=-1.843, p=.070 ; 95 \%$ CI: $[-2.066,0.064])$.

While there were no condition-dependent group differences in

\footnotetext{
${ }^{1}$ The literature is still developing in terms of how to compute power estimates for multilevel models because several factors may impact upon this estimation, namely the number of levels, the type of design, the scale of the variables, among others. Several studies have concluded that even when small samples sizes are used little to no bias is achieved in the estimates of fixed effects (e.g., Clarke and Wheaton, 2007; Maas and Hox, 2005).
}

response to tones $(p>.05)$, NCVH showed a more negative N1 in response to self-initiated voices compared to externally-generated voices $(\beta=1.672, \mathrm{SE}=0.331, t(323)=5.057, p<.001 ; 95 \%$ CI: [1.024, $2.319])$, as well as to self-initiated voices compared to self-initiated tones $(\beta=-0.836, \mathrm{SE}=0.335, t(323)=-2.497, p=.013$; $95 \% \mathrm{CI}$ : $[-1.493,-0.180])$. The enhanced N1 response to self-initiated voices ( $v s$. self-initiated tones) in NCVH was significantly different from controls ( $\beta$ $=0.836, \mathrm{SE}=0.335, t(323)=2.497, p=.013 ; 95 \% \mathrm{CI}$ : $[0.180,1.493])$ and patients $(\beta=1.247, \mathrm{SE}=0.329, t(323)=3.784, p<.001 ; 95 \% \mathrm{CI}$ : $[0.601,1.892])$. The difference between self-initiated and externally generated voices was not significant in patients $(\beta=0.174, \mathrm{SE}=0.331, t$ $(323)=0.525, p>.05 ; 95 \%$ CI: $[-0.474,0.821])$.

P2: A significant effect of condition $(F(1,693)=14.744, p<.001)$ indicated that the $\mathrm{P} 2$ was generally more suppressed (i.e., less positive) in response to self-initiated sounds compared to externally generated sounds $(\beta=0.826, \mathrm{SE}=0.274, t(693)=3.012, p=.003,95 \%$ CI: $[-0.468,0.159]$; see Fig. 2). Group interacted with stimulus type and condition $(F(6,693)=2.338, p=.030)$ indicating that the P2 suppression response (i.e., AMC - AOC difference) was larger in NCVH than in patients $(\beta=-1.126, \mathrm{SE}=0.388, t(693)=-2.905, p=.004,95 \% \mathrm{CI}$ : $[-1.886,-0.366])$ but not in controls $(p>.05)$. Nonetheless, the P2 was generally reduced for voices (both self-initiated and externally generated) but not for tones, in NCVH compared to controls ( $\beta=-1.473$, SE $=0.612, t(54)=-2.409, p=.019,95 \%$ CI: $[-2.672,-0.274]$ ) (see Fig. 2).

\subsection{Readiness Potential}

A slope analysis (see Figs. 3 and 4) revealed that the RP rose much more slowly in patients than in controls and had a lower amplitude. The early RP deflected less negatively in patients than in controls $(\beta=1.432$, $\mathrm{SE}=0.494, t(101)=-2.899, p=.005,95 \%$ CI: $[0.464,2.401])$. The late $\mathrm{RP}$ was less negative in both patients $(\beta=3.332, \mathrm{SE}=0.749, \mathrm{t}(93)=$ 4.446, $p<.001,95 \% \mathrm{CI}:[1.863,4.800])$ and $\mathrm{NCVH}(\beta=1.936$, SE $=$ $0.742, t(91)=-2.610, p=.011,95 \%$ CI: $[0.482,3.390])$ compared to controls. In controls, the early RP was significantly different from zero before actions preceding tones $(p=.016)$ and voices $(p=.013)$, but not before actions with no sensory feedback $(p=.150)$. However, the late RP was significantly different from zero for all conditions (AMC tone $-p<$ .001 , AMC voice $-p<.001, \mathrm{MOC}-p=.009$ ). In NCVH, the late RP was significantly different from zero for all conditions (AMC tone $-p=.034$, AMC voice $-p=.046$, MOC $-p=.036$ ), but not the early RP (AMC tone $p=.167$, AMC voice $-p=.882$, MOC $-p=.141$ ). In patients, both early (AMC tone $-p=.302$, AMC voice $-p=.360$, MOC $-p=.934$ ) and late $\mathrm{RP}$ (AMC tone $-p=.710$, AMC voice $-p=.475, \mathrm{MOC}-p=.630$ ) did not differ significantly from zero for any of the conditions tested.

As previous studies showed that the RP is larger when actions are followed by sensory feedback (Vercillo et al., 2018), we computed the difference between the RP in the MOC and AMC conditions: more positive values indicate a more negative voltage for the AMC compared to the MOC condition. The difference was then included as dependent variable in the statistical model. This additional analysis revealed qualitative differences between controls, $\mathrm{NCVH}$, and patients. Both the early and late RP phases differed significantly by group: the early RP was more negative in the MOC compared to AMC in NCVH $(\beta=-1.003$, SE $=0.470, t(47)=-2.134, p=.038,95 \%$ CI: $[-1.924,-0.082])$, and tended to be more negative in the MOC compared to AMC in patients ( $\beta$ $=-0.898, \mathrm{SE}=0.470, t(47)=-1.911, p=.062,95 \% \mathrm{CI}:[-1.819$, $0.023])$. The late RP phase was more negative in the MOC compared to AMC in patients $(\beta=-1.393, \mathrm{SE}=0.560, t(47)=-2.489, p=.016,95 \%$ CI: $2.490,-0.296])$. Of note, only the early phase of the RP was modulated by stimulus type: relative to controls, NCVH showed a less negative RP (MOC $>$ AMC) when preparing for a voice elicitation than when preparing for a tone elicitation $(\beta=-0.651, \mathrm{SE}=0.287, t(47)=$ $-2.270, p=.028,95 \%$ CI: $[-1.214,-0.089])$. 
1. CTR

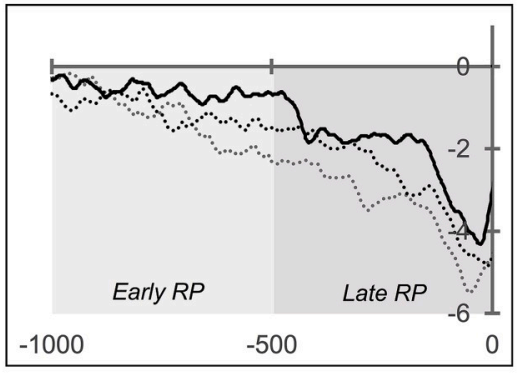

2. $\mathrm{NCVH}$

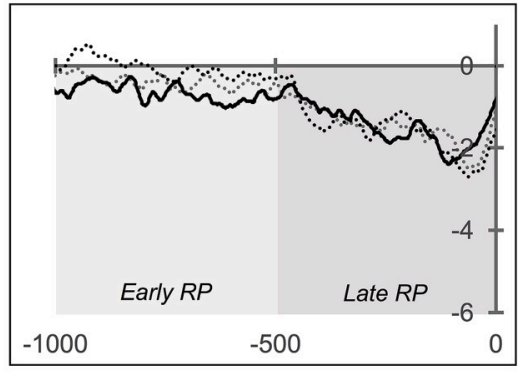

3. PAT

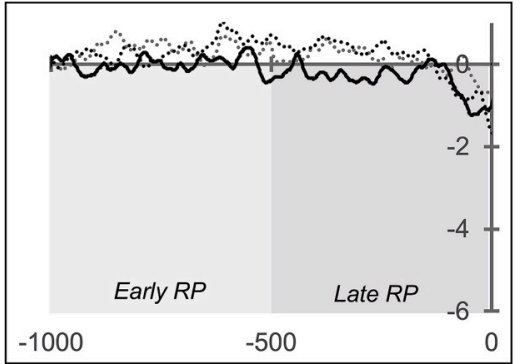

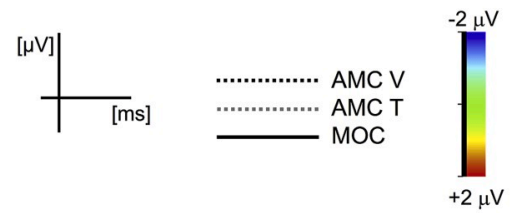

1. CTR

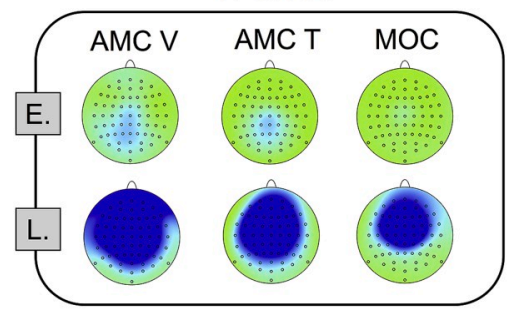

2. $\mathrm{NCVH}$

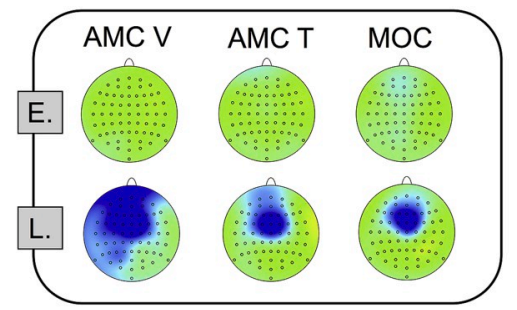

3. PAT

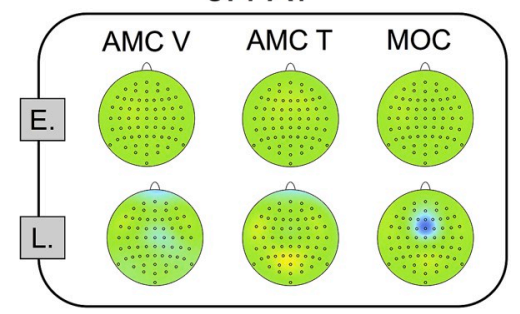

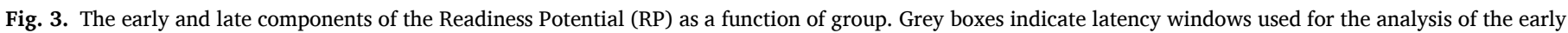

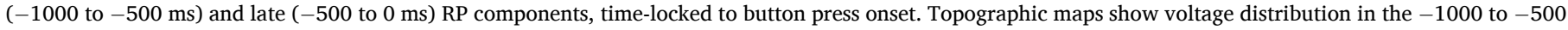

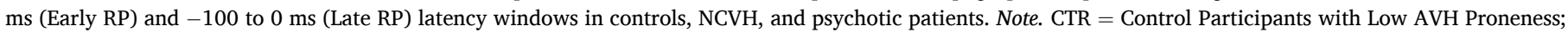

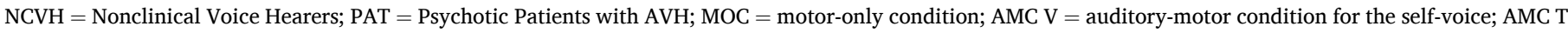
$=$ auditory-motor condition for tones; $\mathrm{E}=$ Early RP; $\mathrm{L}=$ Late RP.

Table 2

Duration of tapping intervals in the auditory-motor and motor-only conditions.

\begin{tabular}{llll}
\hline & AMC Tone & AMC Voice & MOC \\
\hline CTR & $2460.90(241.01)$ & $2440.83(244.38)$ & $2505.17(276.14)$ \\
NCVH & $2472.93(177.05)$ & $2471.90(204.57)$ & $2538.68(195.56)$ \\
PAT & $2331.97(225.05)$ & $2290.55(228.03)$ & $2463.44(286.12)$ \\
\hline
\end{tabular}

Note. CTR $=$ Control Participants; $\mathrm{NCVH}=$ Nonclinical Voice Hearers; PAT $=$ Psychotic Patients; AMC = Auditory-Motor Condition; MOC $=$ Motor-Only Condition. Response times are presented in ms. Standard deviations are shown in parentheses.

\subsection{Relationship between motor and auditory potentials}

The N1 suppression effect was predicted by the RP: in all groups, the more negative the late RP for actions with sensory feedback (AMC > $\mathrm{AOC})$, the larger the N1 suppression effect $(\beta=0.848, \mathrm{SE}=0.391, t(89)$ $=2.170, p=.033,95 \%$ CI: $[0.071,1.631]$. This relationship was stronger when the button presses elicited voices than tones in the early $\mathrm{RP}(\beta=1.722, \mathrm{SE}=0.643, t(56)=2.679, p=.010,95 \% \mathrm{CI}:[0.449$, 3.026]).

\section{Discussion}

By directly comparing psychotic and non-psychotic voice hearers, the current study specified whether AVH proneness similarly affects sensory feedback processing of tones and voices. The results confirm that AVH proneness alters the sensory suppression for the self-voice but not for simple tones. Altered sensory suppression was found in the N1 and P2 components. We also report group differences for preparatory motor activity (RP) that presumably encodes the predicted sensory consequences of voluntary actions (Reznik et al., 2018).

\subsection{The impact of hallucination proneness on self-initiated sound processing}

Typical N1 suppression to tones and voices was replicated in control participants with low AVH proneness. In particular, self-voices elicited a larger N1 response than tones, which might be accounted for by differences in stimulus duration ( $50 \mathrm{~ms}$ for tones; $300 \mathrm{~ms}$ for voices): $\mathrm{N} 1$ amplitude was found to increase linearly with stimulus duration (Ostroff et al., 2003; Rosburg et al., 2008).

We also replicated the finding that higher AVH proneness in $\mathrm{NCVH}$ was associated with $\mathrm{N} 1$ enhancement to self-voice feedback (Pinheiro et al., 2018). In previous studies, both altered sensory prediction (Baess et al., 2008; Behroozmand et al., 2007; Behroozmand and Larson, 2011) and increased attention (Baess et al., 2008; Behroozmand et al., 2007; Behroozmand and Larson, 2011) led to N1 enhancement rather than suppression and the contribution of attention to altered self-voice monitoring in AVH was shown (Ilankovic et al., 2011). Other EEG studies also reported altered neurophysiological responses in NCVH that are consistent with increased attention (i.e., larger P300 amplitudes in an oddball task - van Lutterveld et al., 2010), whereas the reverse finding (i.e., decreased attention) was observed in psychotic patients (Jeon and Polich, 2003). The current findings potentially indicate less accurate or reliable predictions of self-voice feedback in NCVH that could lead to increased attention to self-voice feedback (Pinheiro et al., 2018). Consistent with previous studies (Ford et al., 2001a), the N1 response to self-vs. externally generated voices did not differ in psychotic patients, indicating changes in sensory feedback processing when comparing expected against actual sensation (Ford et al., 2001a), which may reflect altered cerebellar function (Knolle et al., 2013a, 2012). The 


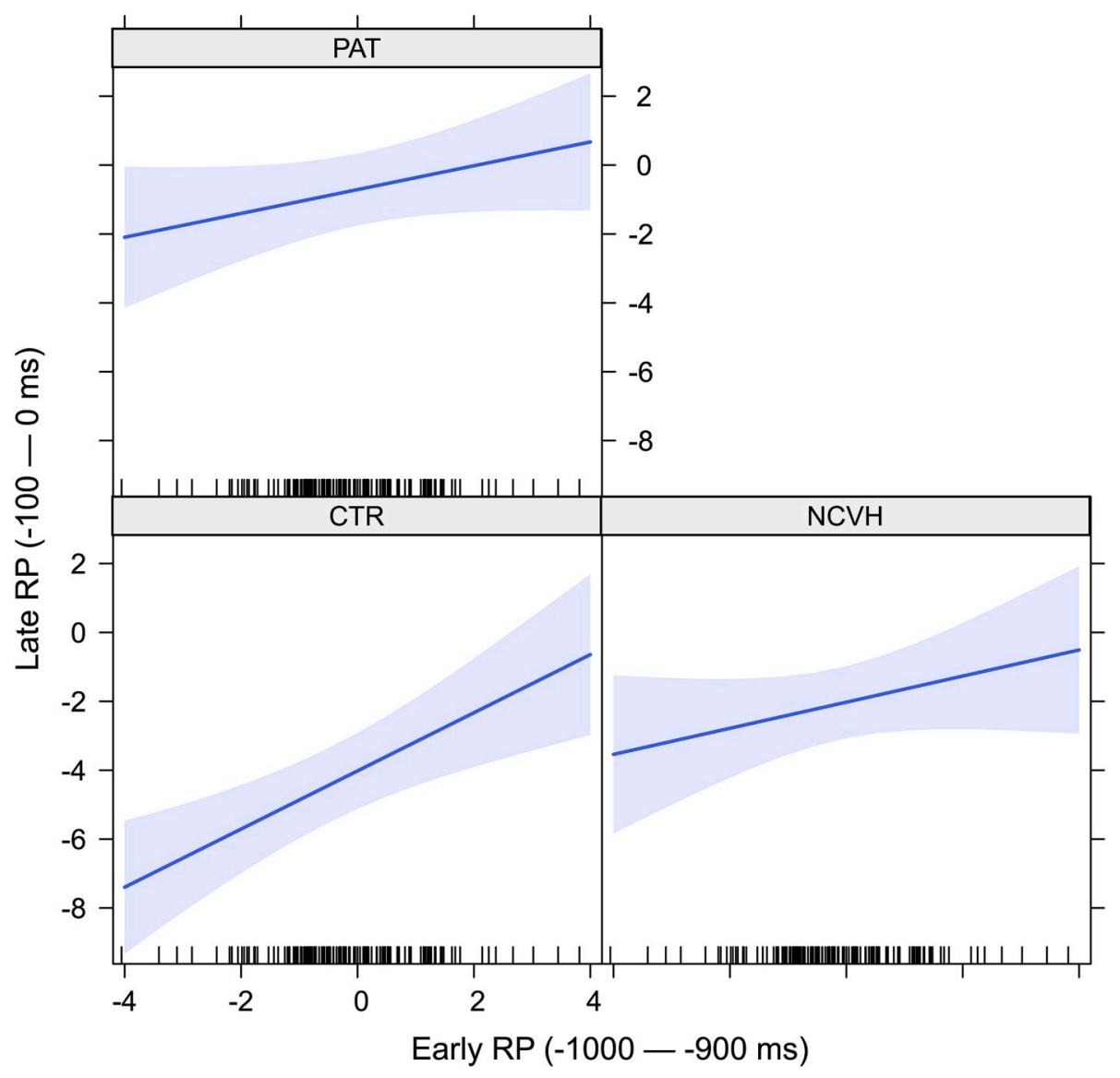

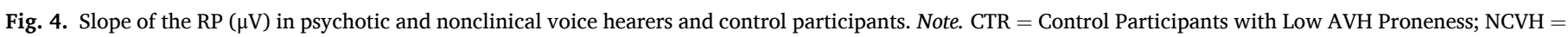
Nonclinical Voice Hearers; PAT $=$ Psychotic Patients with AVH; RP = Readiness Potential. Bars in the $x$ axis represent each participant's data.

alteration of N1 suppression in nonclinical and clinical AVH occurred for voices but not for tones. A less precise prediction may imply altered self-monitoring of the voice as an external sound source (Allen et al., 2004).

In the current study, the globally reduced N1 response in psychotic patients is consistent with evidence for $\mathrm{N} 1$ amplitude reduction in both active and passive tasks in schizophrenia, already observed in firstepisode psychotic patients (Ethridge et al., 2015; Force et al., 2008; Rosburg et al., 2008; Salisbury et al., 2010; van Tricht et al., 2011) and in unaffected first-degree relatives of schizophrenia patients (Foxe et al., 2011). The N1 modulation in first-episode psychotic patients and clinical high-risk participants was therefore considered as an endophenotypic marker for psychosis (Foxe et al., 2011). Of note, the global N1 response of NCVH was intermediate to controls and psychotic patients. In prior studies, the N1 suppression effect in antipsychotic-free clinical high-risk participants has been reported to be intermediate between schizophrenia patients and controls (Perez et al., 2012). NCVH were found to be at a higher risk for developing clinical disorders (Johns et al., 2014). Specifically, both persistence and frequency of psychotic-like experiences such as AVH increase the probability of a psychosis onset (Johns et al., 2014). The current findings warrant longitudinal assessments of this cohort to determine the validity of the N1 as a marker of AVH proneness.

Group differences in the P2, assumed to reflect the conscious detection of a self-initiated sound (Knolle et al., 2013b, 2012), were also observed. P2 suppression for tones and voices was enhanced in NCVH, whereas P2 in patients was similar for self-initiated and externally generated voices. However, the P2 was overall more suppressed in response to voices than tones in NCVH compared to controls. The P2, not the N1, was found to more directly relate to the subjective experience of agency (Timm et al., 2016), i.e., the sense of control over voluntary actions and their sensory consequences. Sensory attenuation to self-generated action consequences is considered an implicit measure of agency (Synofzik et al., 2008). Consequently, any alterations in the P2 could relate to changes in a sense of agency over one's own actions and their sensory effects. Despite an enhanced N1 response, NCVH could still have a preserved feeling of agency compared to psychotic patients, who showed no P2 suppression for voices. Consistent with this hypothesis, phenomenological reports of AVH indicate that, when compared to psychotic patients, NCVH report higher perceived control over the onset and offset of voices and AVH have no relationship with anomalies in the sense of self and identity (Johns et al., 2014). The current findings support the notion that the $\mathrm{N} 1$ and the $\mathrm{P} 2$ reflect two dissociable processes (Crowley and Colrain, 2004), i.e. suppression (N1) and tagging (P2) functions in the forward model (Ford et al., 2014a, 2014b; Knolle et al., 2012, 2013a).

\subsection{The impact of hallucination proneness on motor preparation to sensory feedback}

Preparing for an action is thought to result in the pre-activation of the action's sensory effects (Reznik et al., 2018; Roussel et al., 2013). In previous studies, a larger (i.e., more negative) RP was associated with greater N1 suppression for tones and voices (Ford et al., 2014a, 2014b; Reznik et al., 2018; Vercillo et al., 2018). The current study confirms RP group differences preceding actions with or without sensory consequences. A smaller RP was observed in patients compared to healthy controls (both early and late phases) and NCVH (late phase only), irrespective of condition. The condition-independent RP reduction is consistent with prior studies reporting changes in motor preparation in 
psychosis, suggestive of frontal lobe and cerebellar dysfunction (Kappenman et al., 2016; Luck et al., 2009; Singh et al., 1992). Of note, in the current study the RP was not significantly different from zero in both early and late phases, indicative of motor abnormalities that are already observed in the early stage of psychosis. An intermediate RP pattern was observed in NCVH, similarly to the N1. Notwithstanding, the RP change in NCVH was stimulus-dependent: the early RP phase was smaller in preparation of actions eliciting voices compared to tones. Previous studies found that, compared to the late RP, the early RP seems to reflect the encoding of expected sensory consequences of self-generated actions (Reznik et al., 2018) and is more affected by positive symptoms, such as AVH (Karaman et al., 1997). Changes of the early RP could potentially result from structural changes in the SMA, which engages in the preparation for movements (Ball et al., 1999; Erdler et al., 2000; Praamstra et al., 1996; Weilke et al., 2001; Wildgruber et al., 1997). These findings align with alterations of the efference copy that affect the sensory consequences of an action. The preparation of an action is predictive of its sensory consequences. Thus, an enhanced RP response should be associated with a strong N1 suppression effect. Accordingly, a smaller RP in voice hearers was associated with a change in N1 suppression. Specifically, changes in the motor preparation for voice feedback in NCVH could explain selective changes in the processing of self-generated vocalizations. AVH may arise from an inaccurate efference copy, which does not effectively prepare the auditory cortex for the sensory feedback to the self-voice. It is possible that along the psychosis continuum, altered sensory feedback that is predicted as a function of one's own action, occurs first for auditory stimuli with increased social relevance (e.g., voices) and at clinical stages of the continuum generalizes to other types of sounds (e.g., simple tones).

\subsection{Implications}

A complex combination of continuity and discontinuity in AVH in nonclinical and clinical voice hearers has been noted (Luhrmann et al., 2019; Waters and Fernyhough, 2019). The current findings are in line with an extended psychosis phenotype (Kaymaz and van Os, 2010) and specifically with quasi-dimensional models of hallucinations (Baumeister et al., 2017), proposing that NCVH are at a middle-point between psychotic patients and nonclinical individuals with low AVH proneness (Baumeister et al., 2017). That is, changes in sensory feedback seem to be distributed on a psychosis continuum rather than being specific to psychotic disorders (Randeniya et al., 2018; Van Os et al., 2009). However, the suppression pattern presents qualitative differences between psychotic and nonclinical voice hearers, showing only partial overlap with clinical disorder. Specifically, severe sensory suppression deficits were characteristic of psychotic patients, possibly as a result of disease progression.

A stronger impact of AVH on the processing of self-generated voices supports a model in which part of the neurobiological mechanism underlying AVH is shared between clinical and NCVH (Diederen et al., 2012). It is possible that individual differences in how mechanistic components of the forward model are changed (such as the RP, N1 and P2) could give rise to distinct phenomenological experiences of voice hearing, associated with differences in their clinical outcome (Johns et al., 2014). For example, emotional salience (e.g., negative valence) could affect the neural response to unexpected changes in self-voice feedback (signaling sensory prediction error) differently in psychotic and nonclinical voice hearers. This could explain phenomenological differences in the content of $\mathrm{AVH}$, which are often described as threatening and derogatory in psychotic voice hearers, but less so in nonclinical AVH (e.g., Larøi et al., 2012; McCarthy-Jones et al., 2014b; Nayani and David, 1996). This hypothesis is speculative and needs to be tested in future studies.

These current findings highlight the relevance of the sensorimotor network in the experience of AVH, and its broader role in psychopathology in line with the Research Domain Criteria (RDoC) framework.

\subsection{Limitations}

A major limitation of the current study is the relatively small group sample size. We note, though, that recruitment of nonpsychotic voice hearers represents a challenging process due to concerns about stigma (Alderson-Day et al., 2017). Even though the number of NCVH recruited in the current study is similar to previous studies (for example, $n=12$ in Alderson-Day et al., 2017; $\mathrm{n}=15$ in Powers et al., 2017), the current findings should be interpreted with caution.

Another limitation concerns the use of button-press tasks to study action-related sensory attenuation in self-voice perception. Specifically, the self-voice is perceived differently in speech production (where sound is perceived through air and bone conduction) and in pre-recordings of one's own voice elicited by a button press (where sound is perceived through air conduction only) (Maurer and Landis, 1990). Notwithstanding, previous studies successfully showed that prerecorded self-voice stimuli are recognized as "self" with an accuracy rate above 89\% (Hughes and Nicholson, 2010; Nakamura et al., 2001; Pinheiro et al., 2019; Pinheiro et al., 2016; Rosa et al., 2008). When debriefed, all participants of the current study indicated they recognized the pre-recorded voice as their own voice. However, it is not entirely clear whether preparation for sensory feedback is similar in button-press and speaking tasks, which should be directly compared in future studies.

\subsection{Conclusions}

By directly comparing psychotic and NCVH, the current study investigated AVH proneness and how it modulates the processing of auditory stimuli (tones $v s$. voices) that are anticipated as a consequence of an action. The results indicate that altered neural responses to voice feedback may be core to AVH. Alterations of sensory feedback processing in both psychotic and NCVH are related to changes in preparatory motor activity prior to voluntary actions and their sensory consequences. These findings support quasi-dimensional models of hallucinations that suggest a continuum of psychotic symptoms in the general population.

\section{Disclosures}

The authors reported no biomedical financial interests or potential conflicts of interest.

\section{CRediT authorship contribution statement}

Ana P. Pinheiro: Conceptualization, Methodology, Validation, Investigation, Funding acquisition, Resources, Data curation, Formal analysis, Project administration, Supervision, Visualization, Writing original draft, Writing - review \& editing. Michael Schwartze: Conceptualization, Methodology, Validation, Formal analysis, Visualization, Writing - review \& editing. Maria Amorim: Investigation, Data curation, Formal analysis, Visualization, Writing - review \& editing. Ricardo Coentre: Methodology, Investigation, Resources, Formal analysis, Visualization, Writing - review \& editing. Pedro Levy: Methodology, Investigation, Resources, Formal analysis, Visualization, Writing - review \& editing. Sonja A. Kotz: Conceptualization, Methodology, Validation, Resources, Supervision, Formal analysis, Visualization, Writing - review \& editing.

\section{Acknowledgments}

This work was supported by the Portuguese Science National Foundation (Fundação para a Ciência e a Tecnologia [FCT]; grant numbers IF/00334/2012, PTDC/MHC-PCN/0101/2014 awarded to APP).

The Authors would like to thank all the participants who collaborated in the study, and particularly Dr. Franziska Knolle for feedback on stimulus generation and Dr. Francisco Gutiérrez-Domínguez for help in 
data collection and analysis. Part of the data were presented at the annual meeting of the Society of Biological Psychiatry (Chicago, 2019) and of the Schizophrenia International Research Society (Florence, 2018; Orlando, 2019).

\section{Appendix A. Supplementary data}

Supplementary data to this article can be found online at https://doi. org/10.1016/j.neuropsychologia.2020.107531.

\section{References}

Alderson-Day, B., Lima, C.F., Evans, S., Krishnan, S., Shanmugalingam, P., Fernyhough, C., Scott, S.K., 2017. Distinct processing of ambiguous speech in people with non-clinical auditory verbal hallucinations. Brain 9, 2475-2489. https://doi. org/10.1093/brain/awx206.

Allen, P., Johns, L.C., Fu, C.H.Y., Broome, M.R., Vythelingum, G.N., McGuire, P.K., 2004 Misattribution of external speech in patients with hallucinations and delusions. Schizophr. Res. 69, 277-287. https://doi.org/10.1016/j.schres.2003.09.008.

Baayen, R.H., Davidson, D.J., Bates, D.M., 2008. Mixed-effects modeling with crossed random effects for subjects and items. J. Mem. Lang. 59, 390-412. https://doi.org/ 10.1016/j.jml.2007.12.005.

Baess, P., Horvath, J., Jacobsen, T., Schroger, E., 2011. Selective suppression of selfinitiated sounds in an auditory stream: an ERP study. Psychophysiology 48, 1276-1283. https://doi.org/10.1111/j.1469-8986.2011.01196.x.

Baess, P., Jacobsen, T., Schröger, E., 2008. Suppression of the auditory N1 event-related potential component with unpredictable self-initiated tones: evidence for internal forward models with dynamic stimulation. Int. J. Psychophysiol. 70, 137-143. https://doi.org/10.1016/j.ijpsycho.2008.06.005.

Bagiella, E., Sloan, R.P., Heitjan, D.F., 2000. Mixed-effects models in psychophysiology. Psychophysiology 37, 13-20. https://doi.org/10.1017/S0048577200980648.

Ball, T., Schreiber, A., Feige, B., Wagner, M., Lücking, C.H., Kristeva-Feige, R., 1999. The role of higher-order motor areas in voluntary movement as revealed by highresolution EEG and fMRI. Neuroimage 10, 682-694. https://doi.org/10.1006/ nimg.1999.0507.

Bates, D., Mächler, M., Bolker, B., Walker, S., 2015. Fitting linear mixed-effects models using lme4. J. Stat. Software 67, 1-48. https://doi.org/10.18637/jss.v067.i01.

Baumeister, D., Sedgwick, O., Howes, O., Peters, E., 2017. Auditory verbal hallucinations and continuum models of psychosis: a systematic review of the healthy voice-hearer literature. Clin. Psychol. Rev. 51, 125-141. https://doi.org/10.1016/j. cpr.2016.10.010.

Beavan, V., Read, J., Cartwright, C., 2011. The prevalence of voice-hearers in the general population: a literature review. J. Ment. Health 20, 281-292. https://doi.org/ 10.3109/09638237.2011.562262.

Behroozmand, R., Larson, C.R., 2011. Error-dependent modulation of speech-induced auditory suppression for pitch-shifted voice feedback. BMC Neurosci. 12, 54. https:// doi.org/10.1186/1471-2202-12-54.

Behroozmand, R., Liu, H., Larson, C.R., 2007. Time-dependent neural processing of the auditory feedback during voice pitch error detection. J. Cognit. Neurosci. 23, 1-13. https://doi.org/10.1162/jocn.2010.21447.

Blakemore, S.J., Wolpert, D.M., Frith, C.D., 1998. Central cancellation of self-produced tickle sensation. Nat. Neurosci. 1, 635-640. https://doi.org/10.1038/2870.

Boisgontier, M.P., Cheval, B., 2016. The anova to mixed model transition. Neurosci. Biobehav. Rev. 68, 1004-1005. https://doi.org/10.1016/j.neubiorev.2016.05.034.

Boutros, N.N., Gjini, K., Urbach, H., Pflieger, M.E., 2011. Mapping repetition suppression of the N100 evoked response to the human cerebral cortex. Biol. Psychiatr. 69, 883-889. https://doi.org/10.1016/j.biopsych.2010.12.011.

Brunelin, J., Combris, M., Poulet, E., Kallel, L., D’Amato, T., Dalery, J., Saoud, M., 2006 Source monitoring deficits in hallucinating compared to non-hallucinating patients with schizophrenia. Eur. Psychiatr. 21, 259-261. https://doi.org/10.1016/j. eurpsy.2006.01.015.

Castiajo, P., Pinheiro, A.P., 2017. On "hearing" voices and "seeing" things: probing hallucination predisposition in a Portuguese nonclinical sample with the LaunaySlade Hallucination Scale-revised. Front. Psychol. 8, 1138. https://doi.org/10.3389/ fpsyg. 2017.01138.

Chen, C.A., Mathalon, D.H., Roach, B.J., Cavus, I., Spencer, D.D., Ford, J.M., 2011. The corollary discharge in humans is related to synchronous neural oscillations. J. Cognit. Neurosci. 23, 2892-2904. https://doi.org/10.1162/jocn.2010.21589.

Clarke, P., Wheaton, B., 2007. Addressing data sparseness in contextual population research: using cluster analysis to create synthetic neighborhoods. Socio. Methods Res. 35, 311-351. https://doi.org/10.1177/0049124106292362.

Crowley, K.E., Colrain, I.M., 2004. A review of the evidence for P2 being an independent component process: age, sleep and modality. Clin. Neurophysiol. 115, 732-744. https://doi.org/10.1016/j.clinph.2003.11.021.

Deecke, L., Heise, B., Kornhuber, H.H., Lang, M., Lang, W., 1984. Brain potentials associated with voluntary manual tracking: bereitschaftspotential, conditioned premotion positivity, directed attention potential, and relaxation potential: anticipatory activity of the limbic and frontal cortex. Ann. N. Y. Acad. Sci. 425, 450-464. https://doi.org/10.1111/j.1749-6632.1984.tb23567.x.

Deecke, L., Kornhuber, H.H., 1978. An electrical sign of participation of the mesial "supplementary" motor cortex in human voluntary finger movement. Brain Res. 159, 473-476. https://doi.org/10.1016/0006-8993(78)90561-9.
Di Russo, F., Berchicci, M., Bozzacchi, C., Perri, R.L., Pitzalis, S., Spinelli, D., 2017. Beyond the "Bereitschaftspotential": action preparation behind cognitive functions. Neurosci. Biobehav. Rev. 78, 57-81. https://doi.org/10.1016/j. neubiorev.2017.04.019.

Diederen, K.M.J., Daalman, K., De Weijer, A.D., Neggers, S.F.W., Van Gastel, W., Blom, J. D., Kahn, R.S., Sommer, I.E.C., 2012. Auditory hallucinations elicit similar brain activation in psychotic and nonpsychotic individuals. Schizophr. Bull. 38, 1074-1082. https://doi.org/10.1093/schbul/sbr033.

Doya, K., 1999. What are the computations of the cerebellum, the basal ganglia and the cerebral cortex? Neural Network. 12, 961-974. https://doi.org/10.1016/S08936080(99)00046-5.

Elijah, R.B., Le Pelley, M.E., Whitford, T.J., 2016. Modifying temporal expectations: changing cortical responsivity to delayed self-initiated sensations with training. Biol. Psychol. 120, 88-95. https://doi.org/10.1016/j.biopsycho.2016.09.001.

Erdler, M., Beisteiner, R., Mayer, D., Kaindl, T., Edward, V., Windischberger, C., Lindinger, G., Deecke, L., 2000. Supplementary motor area activation preceding voluntary movement is detectable with a whole-scalp magnetoencephalography system. Neuroimage 11, 697-707. https://doi.org/10.1006/nimg.2000.0579.

Ethridge, L.E., Hamm, J.P., Pearlson, G.D., Tamminga, C.A., Sweeney, J.A., Keshavan, M. S., Clementz, B.A., 2015. Event-related potential and time-frequency endophenotypes for schizophrenia and psychotic bipolar disorder. Biol. Psychiatr. 77, 127-136. https://doi.org/10.1016/j.biopsych.2014.03.032.

Feinberg, I., 1978. Efference copy and corollary discharge: implications for thinking and its disorders. Schizophr. Bull. 4, 636-640. https://doi.org/10.1093/schbul/4.4.636.

Feinberg, I., Guazzelli, M., 1999. Schizophrenia - a disorder of the corollary discharge systems that integrate the motor systems of thought with the sensory systems of consciousness. Br. J. Psychiatry 174, 196-204. https://doi.org/10.1192/ bjp.174.3.196.

First, M.B., Spitzer, R.L., Gibbon, M., Williams, J.B.W., 2002. Structured Clinical Interview for DSM-IV Axis I Diagnosis-Patient Edition (SCID-I/P, version 2.0). Biometric Research Department, New York State Psychiatric Institute, New York, NY.

Force, R.B., Venables, N.C., Sponheim, S.R., 2008. An auditory processing abnormality specific to liability for schizophrenia. Schizophr. Res. 103, 298-310. https://doi.org/ 10.1016/j.schres.2008.04.038.

Ford, J.M., Mathalon, D.H., 2005. Corollary discharge dysfunction in schizophrenia: can it explain auditory hallucinations? Int. J. Psychophysiol. 58, 179-189. https://doi. org/10.1016/j.ijpsycho.2005.01.014.

Ford, J.M., Mathalon, D.H., Heinks, T., Kalba, S., Faustman, W.O., Roth, W.T., 2001a Neurophysiological evidence of corollary discharge dysfunction in schizophrenia. Am. J. Psychiatr. 158, 2069-2071. https://doi.org/10.1176/appi.ajp.158.12.2069.

Ford, J.M., Mathalon, D.H., Kalba, S., Whitfield, S., Faustman, W.O., Roth, W.T., 2001b. Cortical responsiveness during talking and listening in schizophrenia: an eventrelated brain potential study. Biol. Psychiatr. 50, 540-549. https://doi.org/10.1016/ S0006-3223(01)01166-0.

Ford, J.M., Palzes, V.A., Roach, B.J., Mathalon, D.H., 2014a. Did i do that? Abnormal predictive processes in schizophrenia when button pressing to deliver a tone. Schizophr. Bull. 40, 804-812. https://doi.org/10.1093/schbul/sbt072.

Ford, Judith M., Palzes, V.A., Roach, B.J., Mathalon, D.H., 2014b. Did i do that? Abnormal predictive processes in schizophrenia when button pressing to deliver a tone. Schizophr. Bull. 40, 804-812. https://doi.org/10.1093/schbul/sbt072.

Ford, J.M., Roach, B.J., Faustman, W.O., Mathalon, D.H., 2008. Out-of-Synch and out-ofsorts: dysfunction of motor-sensory communication in schizophrenia. Biol. Psychiatr. 63, 736-743. https://doi.org/10.1016/j.biopsych.2007.09.013.

Foxe, J.J., Yeap, S., Snyder, A.C., Kelly, S.P., Thakore, J.H., Molholm, S., 2011. The N1 auditory evoked potential component as an endophenotype for schizophrenia: highdensity electrical mapping in clinically unaffected first-degree relatives, firstepisode, and chronic schizophrenia patients. Eur. Arch. Psychiatr. Clin. Neurosci. 261, 331-339. https://doi.org/10.1007/s00406-010-0176-0.

Friston, K., 2012. Prediction, perception and agency. Int. J. Psychophysiol. 83, 248-252. https://doi.org/10.1016/j.ijpsycho.2011.11.014.

Friston, K., 2005. A theory of cortical responses. Philos. Trans. R. Soc. Lond. B Biol. Sci. 360, 815-836. https://doi.org/10.1098/rstb.2005.1622.

Godey, B., Schwartz, D., De Graaf, J.B., Chauvel, P., Liégeois-Chauvel, C., 2001. Neuromagnetic source localization of auditory evoked fields and intracerebra evoked potentials: a comparison of data in the same patients. Clin. Neurophysiol. 112, 1850-1859. https://doi.org/10.1016/S1388-2457(01)00636-8.

Haggard, P., Miall, R.C., Wade, D., Fowler, S., Richardson, A., Anslow, P., Stein, J., 1995. Damage to cerebellocortical pathways after closed head injury: a behavioural and magnetic resonance imaging study. J. Neurol. Neurosurg. Psychiatry 58, 433-438.

Haggard, P., Whitford, B., 2004. Supplementary motor area provides an efferent signal for sensory suppression. Cognit. Brain Res. 19, 52-58. https://doi.org/10.1016/j. cogbrainres.2003.10.018.

Heinks-Maldonado, T.H., Mathalon, D.H., Houde, J.F., Gray, M., Faustman, W.O., Ford, J.M., 2007. Relationship of imprecise corollary discharge in schizophrenia to auditory hallucinations. Arch. Gen. Psychiatr. 64, 286-296. https://doi.org/ 10.1001/archpsyc.64.3.286.

Horga, G., Schatz, K.C., Abi-Dargham, A., Peterson, B.S., 2014. Deficits in predictive coding underlie hallucinations in schizophrenia. J. Neurosci. 34, 8072-8082. https://doi.org/10.1523/JNEUROSCI.0200-14.2014.

Hughes, S.M., Nicholson, S.E., 2010. The processing of auditory and visual recognition of self-stimuli. Conscious. Cognit. 19, 1124-1134. https://doi.org/10.1016/j. concog.2010.03.001.

Ilankovic, L.M., Allen, P.P., Engel, R., Kambeitz, J., Riedel, M., Müller, N., HennigFast, K., 2011. Attentional modulation of external speech attribution in patients with 
hallucinations and delusions. Neuropsychologia 49, 805-812. https://doi.org/ 10.1016/j.neuropsychologia.2011.01.016.

Ito, M., 2008. Control of mental activities by internal models in the cerebellum. Nat. Rev. Neurosci. 9, 304-313. https://doi.org/10.1038/nrn2332.

Ito, M., 2006. Cerebellar circuitry as a neuronal machine. Prog. Neurobiol. 78, 272-303. https://doi.org/10.1016/j.pneurobio.2006.02.006.

Jaeger, T.F., 2008. Categorical data analysis: away from ANOVAs (transformation or not) and towards logit mixed models. J. Mem. Lang. 59, 434-446. https://doi.org/ 10.1016/j.jml.2007.11.007.

Jeon, Y.W., Polich, J., 2003. Meta-analysis of P300 and schizophrenia: patients, paradigms, and practical implications. Psychophysiology 40, 684-701. https://doi. org/10.1111/1469-8986.00070.

Johns, L.C., Kompus, K., Connell, M., Humpston, C., Lincoln, T.M., Longden, E., Preti, A., Alderson-Day, B., Badcock, J.C., Cella, M., Fernyhough, C., McCarthy-Jones, S., Peters, E., Raballo, A., Scott, J., Siddi, S., Sommer, I.E., Laroi, F., 2014. Auditory verbal hallucinations in persons with and without a need for care. Schizophr. Bull. 40, S255-S264. https://doi.org/10.1093/schbul/sbu005.

Johns, L.C., Van Os, J., 2001. The continuity of psychotic experiences in the general population. Clin. Psychol. Rev. 21, 1125-1141. https://doi.org/10.1016/S02727358(01)00103-9.

Kappenman, E.S., Luck, S.J., Kring, A.M., Lesh, T.A., Mangun, G.R., Niendam, T., Ragland, J.D., Ranganath, C., Solomon, M., Swaab, T.Y., Carter, C.S., 2016. Electrophysiological evidence for impaired control of motor output in schizophrenia. Cerebr. Cortex 26, 1891-1899. https://doi.org/10.1093/cercor/bhu329.

Karaman, T., Özkaynak, S., Yaltkaya, K., Büyükberker, C., 1997. Bereitschaftspotential in schizophrenia. Br. J. Psychiatry 171, 31-34.

Kawato, M., Gomi, H., 1992. A computational model of four regions of the cerebellum based on feedback-error learning. Biol. Cybern. 68, 95-103. https://doi.org/ 10.1007/BF00201431.

Kay, S.R., Fiszbein, A., Opler, L.A., 1987. The positive and negative Syndrome scale (PANSS) for schizophrenia. Schizophr. Bull. 13, 261-276. https://doi.org/10.1093/ schbul/13.2.261.

Kaymaz, N., van Os, J., 2010. Extended psychosis phenotype - yes: single continuum unlikely. Psychol. Med. 40, 1963-1966. https://doi.org/10.1017/ s0033291710000358.

Kelleher, I., Cannon, M., 2011. Psychotic-like experiences in the general population: characterizing a high-risk group for psychosis. Psychol. Med. 41, 1-6. https://doi. org/10.1017/S0033291710001005.

Knolle, F., Schröger, E., Baess, P., Kotz, S.A., 2012. The cerebellum generates motor-toauditory predictions: ERP lesion evidence. J. Cognit. Neurosci. 24, 698-706. https:// doi.org/10.1162/jocn_a_00167.

Knolle, F., Schröger, E., Kotz, S.A., 2013a. Cerebellar contribution to the prediction of self-initiated sounds. Cortex 49, 2449-2461. https://doi.org/10.1016/j. cortex.2012.12.012.

Knolle, F., Schröger, E., Kotz, S.A., 2013b. Prediction errors in self- and externallygenerated deviants. Biol. Psychol. 92, 410-416. https://doi.org/10.1016/j. biopsycho. 2012.11.017.

Kornhuber, H.H., Deecke, L., 1965. Hirnpotentialänderungen bei Willkürbewegungen und passiven Bewegungen des Menschen: bereitschaftspotential und reafferente Potentiale. Pflügers Archiv 284, 1-17. https://doi.org/10.1007/BF00412364.

Kuznetsova, A., Brockhoff, P.B., Christensen, R.H.B., 2017. lmerTest package: tests in linear mixed effects models. J. Stat. Software 82, 1-26. https://doi.org/10.18637/ jss.v082.i13.

Larøi, F., Sommer, I.E., Blom, J.D., Fernyhough, C., Ffytche, D.H., Hugdahl, K., Johns, L. C., McCarthy-Jones, S., Preti, A., Raballo, A., Slotema, C.W., Stephane, M., Waters, F., 2012. The characteristic features of auditory verbal hallucinations in clinical and nonclinical groups: state-of-the-art overview and future directions. Schizophr. Bull. 38, 724-733. https://doi.org/10.1093/schbul/sbs061.

Larøi, F., Van Der Linden, M., 2005. Nonclinical participants' reports of hallucinatory experiences. Can. J. Behav. Sci. 37, 33-43. https://doi.org/10.1037/h0087243.

Levitan, C., Ward, P.B., Catts, S.V., Hemsley, D.R., 1996. Predisposition toward auditory hallucinations: the utility of the Launay-Slade hallucination scale in psychiatric patients. Pers. Indiv. Differ. 21, 287-289. https://doi.org/10.1016/0191-8869(96) 00052-9.

Linscott, R.J., van Os, J., 2013. An updated and conservative systematic review and meta-analysis of epidemiological evidence on psychotic experiences in children and adults: on the pathway from proneness to persistence to dimensional expression across mental disorders. Psychol. Med. 43, 1133-1149. https://doi.org/10.1017 S0033291712001626.

Luck, S.J., Kappenman, E.S., Fuller, R.L., Robinson, B., Summerfelt, A., Gold, J.M., 2009. Impaired response selection in schizophrenia: evidence from the P3 wave and the lateralized readiness potential. Psychophysiology 46, 776-786. https://doi.org/ 10.1111/j.1469-8986.2009.00817.x.

Luhrmann, T.M., Alderson-Day, B., Bell, V., Bless, J.J., Corlett, P., Hugdahl, K., Jones, N. Laroi, F., Moseley, P., Padmavati, R., Peters, E., Powers, A.R., Waters, F., 2019. Beyond trauma: a Multiple pathways approach to auditory hallucinations in clinical and nonclinical populations. Schizophr. Bull. 45, S24-S31.

Luke, S.G., 2017. Evaluating significance in linear mixed-effects models in R. Behav. Res. Methods 49, 1494-1502. https://doi.org/10.3758/s13428-016-0809-y.

Maas, C.J.M., Hox, J.J., 2005. Sufficient sample sizes for multilevel modeling. Methodology 1, 86-92. https://doi.org/10.1027/1614-2241.1.3.86.

Mathalon, D.H., Fedor, M., Faustman, W.O., Gray, M., Askari, N., Ford, J.M., 2002. Response-monitoring dysfunction in schizophrenia: an event-related brain potential study. J. Abnorm. Psychol. 111, 22-41. https://doi.org/10.1037/0021843X.111.1.22.
Maurer, D., Landis, T., 1990. Role of bone conduction in the self-perception of speech. Folia Phoniatrica Logop. 42, 226-229. https://doi.org/10.1159/000266070.

McCarthy-Jones, S., Trauer, T., MacKinnon, A., Sims, E., Thomas, N., Copolov, D.L., 2014. A new phenomenological survey of auditory hallucinations: evidence for subtypes and implications for theory and practice. Schizophr. Bull. 40, 225-235. https://doi.org/10.1093/schbul/sbs156.

Moritz, S., Larøi, F., 2008. Differences and similarities in the sensory and cognitive signatures of voice-hearing, intrusions and thoughts. Schizophr. Res. 102, 96-107. https://doi.org/10.1016/j.schres.2008.04.007.

Näätänen, R., Michie, P.T., 1979. Early selective-attention effects on the evoked potential: a critical review and reinterpretation. Biol. Psychol. 8, 81-136. https:// doi.org/10.1016/0301-0511(79)90053-X.

Näätänen, R., Picton, T., 1987. The N1 wave of the human electric and magnetic response to sound: a review and an analysis of the component structure. Psychophysiology 24, 375-425. https://doi.org/10.1111/j.1469-8986.1987. tb00311.x.

Nakamura, K., Kawashima, R., Sugiura, M., Kato, T., Nakamura, A., Hatano, K., Nagumo, S., Kubota, K., Fukuda, H., Ito, K., Kojima, S., 2001. Neural substrates for recognition of familiar voices: a PET study. Neuropsychologia 39, 1047-1054. https://doi.org/10.1016/S0028-3932(01)00037-9.

Nayani, T.H., David, A.S., 1996. The auditory hallucination: a phenomenological survey. Psychol. Med. 26, 177-189. https://doi.org/10.1017/S003329170003381X.

Oestreich, L.K.L., Mifsud, N.G., Ford, J.M., Roach, B.J., Mathalon, D.H., Whitford, T.J., 2016. Cortical suppression to delayed self-initiated auditory stimuli in schizotypy. Clin. EEG Neurosci. 47, 3-10. https://doi.org/10.1177/1550059415581708.

Oldfield, R.C., 1971. The assessment and analysis of handedness: the Edinburgh inventory. Neuropsychologia 9, 97-113. https://doi.org/10.1016/0028-3932(71) 90067-4.

Ostroff, J.M., McDonald, K.L., Schneider, B.A., Alain, C., 2003. Aging and the processing of sound duration in human auditory cortex. Hear. Res. 181, 1-7. https://doi.org/ 10.1016/S0378-5955(03)00113-8.

Perez, V.B., Ford, J.M., Roach, B.J., Loewy, R.L., Stuart, B.K., Vinogradov, S., Mathalon, D.H., 2012. Auditory cortex responsiveness during talking and listening: early illness schizophrenia and patients at clinical high-risk for psychosis. Schizophr. Bull. 38, 1216-1224. https://doi.org/10.1093/schbul/sbr124.

Pinheiro, A.P., Farinha-Fernandes, A., Roberto, M.S., Kotz, S.A., 2019. Self-voice perception and its relationship with hallucination predisposition. Cognit. Neuropsychiatry 24, 237-255.

Pinheiro, A.P., Rezaii, N., Nestor, P.G., Rauber, A., Spencer, K.M., Niznikiewicz, M., 2016. Did you or I say pretty, rude or brief? An ERP study of the effects of speaker's identity on emotional word processing. Brain Lang. 153-154, 38-49. https://doi. org $/ 10.1016 / \mathrm{j}$. bandl.2015.12.003.

Pinheiro, A.P., Schwartze, M., Kotz, S.A., 2018. Voice-selective prediction alterations in nonclinical voice hearers. Sci. Rep. 8, 14717. https://doi.org/10.1038/s41598-01832614-9.

Powers, A.R., Mathys, C., Corlett, P.R., 2017. Pavlovian conditioning-induced hallucinations result from overweighting of perceptual priors. Science (80- 357, 596-600. https://doi.org/10.1126/science.aan3458.

Praamstra, P., Stegeman, D.F., Horstink, M.W.I.M., Cools, A.R., 1996. Dipole source analysis suggests selective modulation of the supplementary motor area contribution to the readiness potential. Electroencephalogr. Clin. Neurophysiol. 98, 468-477.

Randeniya, R., Oestreich, L.K.L., Garrido, M.I., 2018. Sensory prediction errors in the continuum of psychosis. Schizophr. Res. 191, 109-122. https://doi.org/10.1016/j schres.2017.04.019.

Reznik, D., Simon, S., Mukamel, R., 2018. Predicted sensory consequences of voluntary actions modulate amplitude of preceding readiness potentials. Neuropsychologia 119, 302-307. https://doi.org/10.1016/j.neuropsychologia.2018.08.028.

Rosa, C., Lassonde, M., Pinard, C., Keenan, J.P., Belin, P., 2008. Investigations of hemispheric specialization of self-voice recognition. Brain Cognit. 68, 204-214. https://doi.org/10.1016/j.bandc.2008.04.007.

Rosburg, T., Boutros, N.N., Ford, J.M., 2008. Reduced auditory evoked potential component N100 in schizophrenia-a critical review. Psychiatr. Res. 161, 259-274. https://doi.org/10.1016/j.psychres.2008.03.017.

Roussel, C., Hughes, G., Waszak, F., 2013. A preactivation account of sensory attenuation. Neuropsychologia 51, 922-929. https://doi.org/10.1016/j. neuropsychologia.2013.02.005.

Salisbury, D.F., Collins, K.C., McCarley, R.W., 2010. Reductions in the N1 and P2 auditory event-related potentials in first-hospitalized and chronic schizophrenia. Schizophr. Bull. 36, 991-1000. https://doi.org/10.1093/schbul/sbp003.

SanMiguel, I., Todd, J., Schröger, E., 2013. Sensory suppression effects to self-initiated sounds reflect the attenuation of the unspecific N1 component of the auditory ERP. Psychophysiology 50, 334-343. https://doi.org/10.1111/psyp.12024.

Schröger, E., Kotz, S.A., SanMiguel, I., 2015. Bridging prediction and attention in current research on perception and action. Brain Res. 1626, 1-13. https://doi.org/10.1016/ j.brainres.2015.08.037.

Shibasaki, H., Hallett, M., 2006. What is the Bereitschaftspotential? Clin. Neurophysiol. 117, 2341-2356. https://doi.org/10.1016/j.clinph.2006.04.025.

Singh, J., Knight, R.T., Rosenlicht, N., Kotun, J.M., Beckley, D.J., Woods, D.L., 1992. Abnormal premovement brain potentials in schizophrenia. Schizophr. Res. 8, 31-41. https://doi.org/10.1016/0920-9964(92)90058-D.

Synofzik, M., Thier, P., Leube, D.T., Schlotterbeck, P., Lindner, A., 2010. Misattributions of agency in schizophrenia are based on imprecise predictions about the sensory consequences of one's actions. Brain 133, 262-271. https://doi.org/10.1093/brain/ awp291. 
Synofzik, M., Vosgerau, G., Newen, A., 2008. Beyond the comparator model: a multifactorial two-step account of agency. Conscious. Cognit. 17, 219-239. https:// doi.org/10.1016/j.concog.2007.03.010.

Timm, J., Schönwiesner, M., Schröger, E., SanMiguel, I., 2016. Sensory suppression of brain responses to self-generated sounds is observed with and without the perception of agency. Cortex 80, 5-20. https://doi.org/10.1016/j.cortex.2016.03.018.

van Lutterveld, R., Oranje, B., Kemner, C., Abramovic, L., Willems, A.E., Boks, M.P.M., Glenthøj, B.Y., Kahn, R.S., Sommer, I.E.C., 2010. Increased psychophysiological parameters of attention in non-psychotic individuals with auditory verbal hallucinations. Schizophr. Res. 121, 153-159. https://doi.org/10.1016/j. schres.2010.04.017.

Van Os, J., Linscott, R.J., Myin-Germeys, I., Delespaul, P., Krabbendam, L., 2009. A systematic review and meta-analysis of the psychosis continuum: evidence for a psychosis proneness-persistence-impairment model of psychotic disorder. Psychol. Med. 39, 179-195. https://doi.org/10.1017/S0033291708003814.

van Tricht, M.J., Nieman, D.H., Koelman, J.H.T.M., Bour, L.J., van der Meer, J.N., van Amelsvoort, T.A., Linszen, D.H., de Haan, L., 2011. Auditory ERP components before and after transition to a first psychotic episode. Biol. Psychol. 87, 350-357. https:// doi.org/10.1016/j.biopsycho.2011.04.005.

Vercillo, T., O'Neil, S., Jiang, F., 2018. Action-effect contingency modulates the readiness potential. Neuroimage 183, 273-279. https://doi.org/10.1016/j. neuroimage.2018.08.028.

Verdoux, H., Van Os, J., 2002. Psychotic symptoms in non-clinical populations and the continuum of psychosis. Schizophr. Res. 54, 59-65. https://doi.org/10.1016/S09209964(01)00352-8. von Holst, E., 1954. Relations between the central Nervous System and the peripheral organs. Br. J. Anim. Behav. 2, 89-94. https://doi.org/10.1016/S0950-5601(54) 80044-X.

Wang, J., Mathalon, D.H., Roach, B.J., Reilly, J., Keedy, S.K., Sweeney, J.A., Ford, J.M., 2014. Action planning and predictive coding when speaking. Neuroimage 91, 91-98. https://doi.org/10.1016/j.neuroimage.2014.01.003.

Waters, F., Fernyhough, C., 2019. Auditory Hallucinations: does a continuum of severity entail continuity in mechanism? Schizophr. Bull. 45, 717-719. https://doi.org/ $10.1093 /$ schbul/sbz002.

Waters, F., Fernyhough, C., 2017. Hallucinations: a systematic review of points of similarity and difference across diagnostic classes. Schizophr. Bull. 38, 683-692. https://doi.org/10.1093/schbul/sbw132.

Weilke, F., Spiegel, S., Boecker, H., von Einsiedel, H.G., Conrad, B., Schwaiger, M., Erhard, P., 2001. Time-resolved fMRI of activation patterns in M1 and SMA during complex voluntary movement. J. Neurophysiol. 85, 1858-1863. https://doi.org/ 10.1152/jn.2001.85.5.1858.

Wildgruber, D., Erb, M., Klose, U., Grodd, W., 1997. Sequential activation of supplementary motor area and primary motor cortex during self-paced finger movement in human evaluated by functional MRI. Neurosci. Lett. 227, 161-164. https://doi.org/10.1016/S0304-3940(97)00329-7.

Wolpert, D.M., Miall, R.C., Kawato, M., 1998. Internal models in the cerebellum. Trends Cognit. Sci. 2, 338-347. https://doi.org/10.1016/S1364-6613(98)01221-2.

Zouridakis, G., Simos, P.G., Papanicolaou, A.C., 1998. Multiple bilaterally asymmetric cortical sources account for the auditory N1m component. Brain Topogr. 10, 183-189. https://doi.org/10.1023/A:1022246825461. 